\title{
An Integrated Methodology for Design of Tailor-Made Blended Products
}

\author{
Yunus, Nor Alafiza; Gernaey, Krist; Woodley, John; Gani, Rafiqul
}

Published in:

Proceedings of the 22nd European Symposium on Computer Aided Process Engineering

Link to article, DOI:

10.1016/B978-0-444-59520-1.50009-9

Publication date:

2012

Link back to DTU Orbit

Citation $(A P A)$ :

Yunus, N. A., Gernaey, K., Woodley, J., \& Gani, R. (2012). An Integrated Methodology for Design of Tailor-Made Blended Products. In Proceedings of the 22nd European Symposium on Computer Aided Process Engineering (pp. 752-756). Elsevier. Computer Aided Chemical Engineering Vol. 30 https://doi.org/10.1016/B978-0-44459520-1.50009-9

\section{General rights}

Copyright and moral rights for the publications made accessible in the public portal are retained by the authors and/or other copyright owners and it is a condition of accessing publications that users recognise and abide by the legal requirements associated with these rights.

- Users may download and print one copy of any publication from the public portal for the purpose of private study or research.

- You may not further distribute the material or use it for any profit-making activity or commercial gain

- You may freely distribute the URL identifying the publication in the public portal 


\title{
An Integrated Methodology for Design of Tailor- Made Blended Products
}

\author{
Nor Alafiza Yunus, Krist V. Gernaey, John M. Woodley and Rafiqul Gani \\ Department of Chemical and Biochemical Engineering, Søltofts Plads, Building 229, \\ Technical University of Denmark, 2800 Kgs. Lyngby, Denmark.
}

\begin{abstract}
A computer-aided methodology has been developed for the design of blended (mixture) products. Through this methodology, it is possible to identify the most suitable chemicals for blending, and "tailor" the blend according to specified product needs. The methodology has three stages: 1) product design, 2) process identification, and 3) experimental verification. The principle problem, which is the product design stage is divided into four sub-problems and solved with a decomposition-based approach. In stage two, the ability to produce the chemicals used as building blocks in the blends is analyzed. Finally, experimental work (or detailed model-based verification) is conducted in stage three to validate the selected blend candidates. In this study, the product design stage is highlighted through a case study of gasoline blends with biobased chemicals. The objective of this study is to identify blended gasoline products that match (or improve) the performance of the conventional gasoline.
\end{abstract}

Keywords: product design; chemical blends; decomposition method; gasoline

\section{Introduction}

An important issue for the production of many chemical-based products is related to the future supply of essential raw materials. Currently, many of these products are derived from fossil-based resources and from a sustainability point of view, other renewable alternatives need to be considered. In order to achieve this, new products need to be developed by blending conventional materials with bio-based chemicals. A bio-based chemical is defined as one that has the potential to be produced from renewable resources such as biomass or the glycerol by-product from biodiesel production. Blending could offer several advantages, such as, reducing the fossil-based resource consumption, decreasing pollution and increasing product safety. In addition, the product attributes can potentially also be improved by blending. However, the product performance may decline when other chemicals are added. In order to maintain/improve the blended product performance, it is necessary to identify the best product blend with the most appropriate chemicals.

As the number of alternatives can be very large, an experimental search to find the optimal blend is almost impossible. Therefore, a computer-aided methodology to design blended products has been developed. The objective is to quickly and reliably reduce the search space and to identify a few potential candidates for the optimal blended product, which can then be verified (experimentally or with detailed modelling). In this paper, the product design issues are highlighted by considering exclusively chemicals from known bio-based resources and therefore, the second stage of process identification is not necessary. 


\section{Blend Design Methodology}

Figure 1 illustrates the computer-aided blend design methodology for tailor-made chemical blends. The methodology is divided into three stages: 1) Product design stage, where a model-based technique is applied to formulate the chemical blends. 2) Process identification stage; here the feasible processes to produce the chemicals that are to be used as building blocks in the blends are investigated and identified, and 3) the experimental verification stage, where the chemical blends are verified experimentally. The product design stage has four key tasks [1]. First, the design problem is defined where the product needs are identified, translated into target properties and given target values. Secondly, target property models are retrieved from a property model library developed specifically for this methodology. Thirdly, a mixture/blend design algorithm is applied to obtain the mixtures/blends that match the set of constraints (design targets). This algorithm employs a decomposition based solution strategy [2], where, in each successive step, the search space is reduced by screening out alternatives by considering property constraints according to a pre-determined hierarchy. The result is a set of blends that match the constraints, the composition of the chemicals present in the blend, values of the target properties and information about their miscibility. Finally, the mixture target property values are verified by means of rigorous models for the properties and mixtures.

The second stage is only needed if the chemicals used as building blocks in the blends are unknown. However, if the availability of the processes to produce biobased chemicals is a priori identified (e.g. from patents, journals and articles), this stage is not necessary. In the last stage, experimental work will be performed as required, in order to validate the formulated blend/ mixture products.

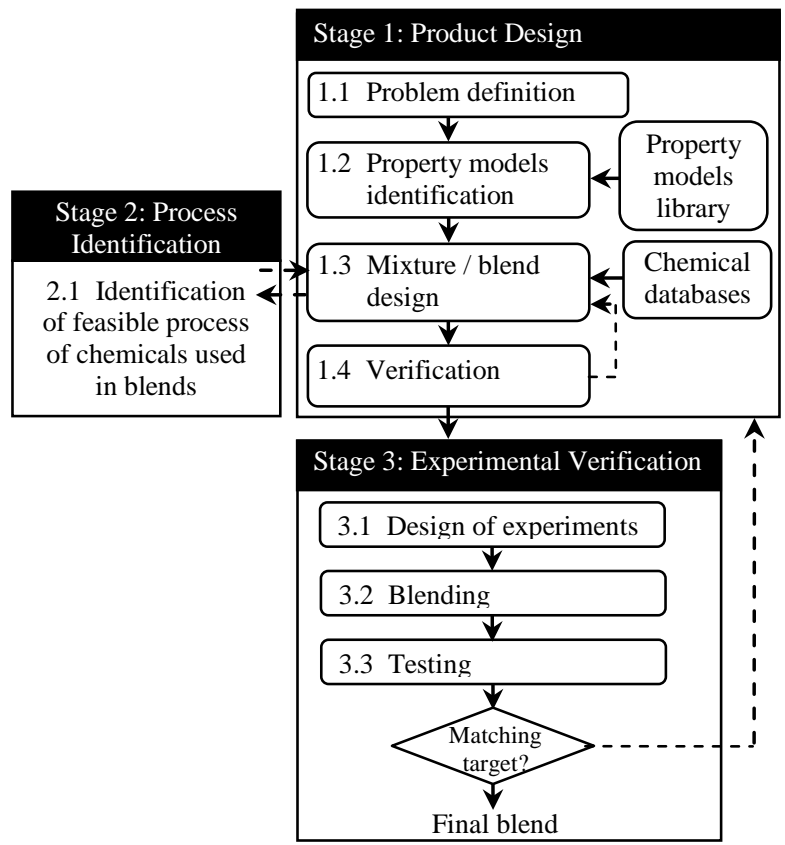

Fig.1: Integrated methodology of blended products design

\section{Case Study}

3.1 Problem definition: For gasoline, the following two issues need to be considered among others: the first is related to the security (or availability) of crude oil supply, and the second is related to the presence of toxic constituents in gasoline that are harmful to the environment as well as to humans. As an alternative, gasoline blended with chemicals derived from renewable sources has the potential to address these issues. Adding bio-based chemicals can reduce the crude oil consumption and the amount of released toxic chemicals. The new formulation of gasoline blends should have good fuel performance, where it can flow continuously from the fuel tank to the combustion chamber, can be burned and can run the engine efficiently. It has to have a suitable 
flammability limit to make sure it only burns at a certain temperature, and low toxicity for reasons of safety. In addition, the gasoline blends must be stable, meaning that the blends do not evaporate easily; do not oxidize to form unwanted by-products, such as gums, sludge and deposits during storage; and must not split into two liquid phases. Furthermore, environmental regulations need to be considered when designing the gasoline blends with oxygenated compounds.

The objective of this case study is to design gasoline blends that are suitable for a car (spark-ignition type) engine and used in a hot climate with average ambient temperature of $27^{\circ} \mathrm{C}$. Gasoline is chosen as the main ingredient in the blends. The bio-based chemicals used as building blocks in the blend formulation have a low carbon number, C2 to C5 alcohols, ethers, ketones, acids and furan derivatives. The blends may consist of two or more chemicals (in addition to the gasoline chemicals) to form either binary or multi-component mixtures of additives.

The first task is to translate the performance criteria into a set of properties with target values. The following properties are considered; consistency of fuel flow is related to viscosity and density; burning ability and evaporation rate are controlled by Reid vapor pressure (RVP); smooth engine operation is related to the octane rating and heating value; flammability limit is controlled by the flash point; toxicity is quantified by the lethal concentration $\left(\mathrm{LC}_{50}\right)$ parameter; stability of blends can be evaluated from Gibbs energy of mixing $\left(\Delta \mathrm{G}^{\mathrm{mix}}\right)$; and the regulations and emissions are related to oxygen content (weight percent). Meanwhile, the oxidation reaction can be avoided by selecting only saturated bio-based chemicals and by avoiding unsaturated chemicals, such as olefins. The needs, translated into target properties and values are summarized in Table 1.

Table 1: The needs of the fuel blend, translated into target properties and constraints set as lower bound (LB) and upper bound (UB) $[3,4]$

\begin{tabular}{|c|c|c|c|c|c|}
\hline Product needs: & Target properties: & Symbol: & UoM: & LB: & UB: \\
\hline \multirow{2}{*}{$\begin{array}{l}\text { 1. Consistency of flow } \\
\text { in engine }\end{array}$} & \multirow{2}{*}{$\begin{array}{l}\text { Dynamic viscosity, } \\
\text { density }\end{array}$} & $\mu$ & сP & 0.3 & 0.6 \\
\hline & & $\rho(V)$ & $\mathrm{L} / \mathrm{kmol}$ & 129 & 139 \\
\hline 2. The ability to burn & Reid vapor pressure & $R V P$ & $\mathrm{kPa}$ & 45 & 60 \\
\hline \multirow[t]{2}{*}{ 3. Engine efficiency } & Octane rating, & RON & - & 92 & 100 \\
\hline & heating value & $H H V$ & $\mathrm{MJ} / \mathrm{kg}$ & 35 & $+\infty$ \\
\hline 4. Flammability & Flash point & $T_{f}$ & K & $-\infty$ & 300 \\
\hline 5. Toxicity & Lethal concentration & $-\log L C_{50}$ & $\mathrm{~mol} / \mathrm{L}$ & $-\infty$ & 3.08 \\
\hline 6. Stability & $\begin{array}{l}\text { Gibbs energy of } \\
\text { mixing }\end{array}$ & $\Delta G_{m i x}$ & - & $-\infty$ & 0 \\
\hline $\begin{array}{l}\text { 7. Blend regulatory } \\
\text { issues and emissions }\end{array}$ & Oxygen content & $W t_{O 2}$ & - & 2 & 20 \\
\hline 8. Low oxidation rate & \multicolumn{5}{|c|}{ Choice of the bio-based chemicals } \\
\hline
\end{tabular}

3.2 Problem formulation: The gasoline blend problem is formulated as a Mixed Integer Non-Linear Programming (MINLP) problem, where the fuel composition is to be optimised, subject to product attributes (target properties) and process specifications. Considering the multiple types of constraint equations, the general gasoline blend problem is formulated as:

Subject to

$$
\min f_{o b j}(x, y)
$$

Mixture constraints: $\quad g_{1}(x, y) \leq 0$ 


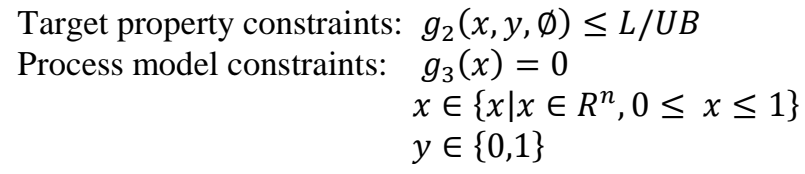

$f_{o b j}$ is the objective function to minimize the gasoline consumption; $y$ is a binary integer variable, which is allied to the identities of the chemicals; $x$ is a continuous variable, which is related to the mixture compositions; while $\emptyset$ corresponds to pure properties; L/UB is the lower and/or upper limit set in Task 1.1 (see Table 1); $g_{1}$ and $g_{2}$ are the mixture and target property constraints, respectively, while the process model constraint is represented by $g_{3}$. The pure properties are estimated using Eq.1, where $\theta$ is molecular structure parameters. The mixture constraint is related with the blend miscibility. It is evaluated using excess Gibbs energy of mixing (see Eq.2). In order to have a stable single-phase mixture, $\Delta \mathrm{G}^{\mathrm{mix}}$ and its first and second derivatives must be continuous functions of $x_{i}$ and the second derivative (Eq.3) must everywhere be positive at constant pressure and temperature. The stability algorithm is used for the mixture stability calculation [5]. Six of the target property constraints $(\mu, \rho(V), R O N$, $H H V,-\log L C_{50}$, and $W t_{O 2}$ ) can be evaluated from linear mixing rules shown by Eq. 4, where TP is the target property, $x_{i}$ is mass or volume percent of compound $i$, and $\emptyset_{i}$ represents the properties of a pure compound, $i$. Meanwhile, RVP and flash point of blends must satisfy Eq. 5 and Eq. 6 respectively [6].

$$
\begin{array}{lll}
\phi_{i}=f(y, \theta) & (1), & \frac{\Delta G^{\text {mix }}}{R T}=\sum x_{i} \ln x_{i}+\frac{G^{E}}{R T} \\
\frac{d^{2} G^{\text {mix }}}{d x_{i}^{2}}>0 & \text { (3), } & T P=\sum x_{i} \phi_{i} \\
\sum \frac{x_{i} \gamma_{i} P_{i}^{\text {sat }}(T)}{R V P_{B}}=1 & \text { (5), } & \sum \frac{x_{i} \gamma_{i} P_{i}^{\text {sat }}}{P_{i, f p}^{\text {sat }}}=1
\end{array}
$$

\section{Solution Strategy using Decomposition Method}

4.1 Solution strategy: The blending problem is solved using a decomposition-based method, where it is divided into four sub-problems, arranged from the simplest to most complex. The first sub-problem eliminates the number of alternatives using pure component properties that are set at a lower and upper limit. The second sub-problem is to screen only miscible mixtures using the stability algorithm [5]. Subsequently, the stable mixtures are further reduced by considering the linear target properties. In this sub-problem, a set of linear target properties are calculated simultaneously, and the blends that match the target values are found. Afterwards, the non-linear constraints are considered in the last sub-problem. At this point, the number of alternatives has been significantly reduced, and it is easier to manage the complexity for a small number of alternatives. Finally, the blend formulations are optimized according to the objective function, which is to minimize the gasoline consumption.

4.2 Methodology Results: Initially, a total of 18 chemicals were listed as bio-based chemicals, which can formulate 900 and 187,400 alternatives for binary and ternary mixtures, respectively. At the first sub-problem, 7 chemicals were removed due to their flash point (greater than $316 \mathrm{~K}$ ), viscosity (greater than $35 \mathrm{cP}$ ) and vapor pressure $(800 \mathrm{kPa})$. High viscosity and flash point may cause difficulty in spraying the fuel and 
forming droplets, for burning in the engine. The remaining 11 chemicals are ethanol, propanol, butanol, IPA, MPA, MBA, acetone, 2-butanone, THF, THFC and MeTHF, which can generate 68,000 alternatives at different compositions $\left(x_{i}: 0.01-0.99\right)$. Then, in the second sub-problem, about 6,800 of the immiscible blends are removed, including partially miscible blends. This is to avoid phase separation in the engine. Subsequently, 8,000 alternatives are left which match the linear target values and the number of alternatives is reduced further to only 320 blends in the last sub-problem. Finally, the top five blends with the minimum gasoline composition are listed in Table 2 with their target properties and values. The compositions (vol\%) and HHV also used as the criteria in the selection with minimum $10 \%$ of volume, and $\mathrm{HHV}$ of blends are close to conventional gasoline (44 $47 \mathrm{MJ} / \mathrm{kg}$ ). RON value cannot be predicted for all blends due to missing pure ON properties so there are also removed. Experiments can now be performed on them.

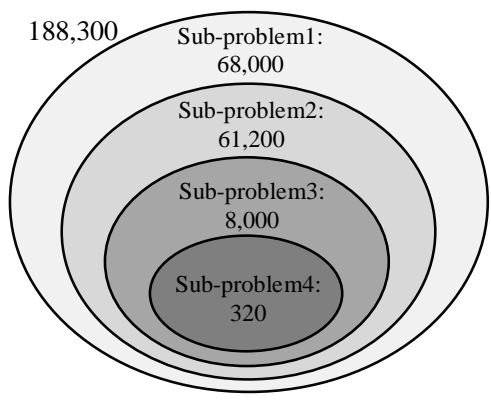

Fig. 2: Number of alternatives reduced with decomposition approach

Table 2: Mixtures matching the target properties and their estimated property values

\begin{tabular}{|c|c|c|c|c|c|c|c|c|c|}
\hline \# & \multicolumn{3}{|c|}{ Composition (vol\%)- $f_{o b j}$} & $\mathrm{HHV}$ & $W t_{02}$ & $R \boldsymbol{R} P$ & RON & $\mu$ & $L C_{50}$ \\
\hline 1 & G (67) & $\mathrm{A}(13)$ & MeTHF(20) & 41 & 7.8 & 46 & - & 0.47 & 2.7 \\
\hline 2 & G (69) & THF (11) & MeTHF(20) & 41 & 7.2 & 46 & - & 0.48 & 2.7 \\
\hline 3 & G (72) & $\mathrm{A}(10)$ & $\mathrm{BE}(18)$ & 40 & 7.3 & 49 & - & 0.48 & 2.7 \\
\hline 4 & G (75) & $\mathrm{BE}(13)$ & MeTHF(12) & 43 & 5.5 & 45 & - & 0.50 & 2.9 \\
\hline 5 & G(77) & E (12) & MeTHF(11) & 42 & 6.7 & 45 & 96 & 0.57 & 2.8 \\
\hline
\end{tabular}

Gasoline(G); Ethanol(E); n-Propanol (P); n-Butanol (B); Acetone (A); 2-Butanone (BE); Isopropanol(IPA); 2methyl-1-propanol(MPA); 3-methyl-1-butanol(MBA); 2-Furancarboxaldehyde, tetrahydro-(THFC);

Tetrahydrofuran(THF); Furan, tetrahydro-2-methyl-(MeTHF)

\section{Conclusions and Future Work}

An integrated methodology for design of tailor-made blended products has been proposed, and the first stage of product design has been highlighted with a case study of a gasoline blend. A decomposition-based method has been applied in solving the blending problem, which is a good approach for reducing a large number of alternatives and a large search space. Current work considers only the product design using a modelbased method. Further verification is needed to verify the blended products and also the methodology. Future work will furthermore test and validate the methodology for other types of blended products to extend the capability of the developed methodology.

\section{References}

[1] Klein, J. A., Wu, D. T., \& Gani, R. (1992). Comp. \& Chem. Eng., 16, S229-S236.

[2] Karunanithi, A. T., Achenie, L. E. K., \& Gani, R. (2005). Ind. Eng. Chem. Res., 44(13), 47854797 .

[3] van Basshuysen, R., Schäfer, F. (2004). Internal Combustion Engine Handbook - Basics, Components, Systems, and Perspectives. USA, Society of Automotive Engineers, Inc.

[4] Forsythe, W.E. (2003). Smithsonian Physical Tables. New York, Knovel. (pp: 322).

[5] Conte, E., Gani, R., \& Ka Ming Ng. (2011). AIChE Journal, 57(9), 2431-2449.

[6] Liaw, H., Tang, C., \& Lai, J. (2004). Combustion and Flame, 138(4), 308-319. 